\title{
Sociabilidades adolescentes na escola básica: estado da arte 2004-2013
}

\author{
Anderson Patrick Rodrigues* \\ Universidade Federal do Pará \\ Wilma de Nazaré Baia Coelho** \\ Universidade Federal do Pará
}

Resumo Este artigo objetiva analisar o que dizem Teses e Dissertações sobre sociabilidades adolescentes na Escola Básica, defendidas em Programas de Pós-graduação brasileiros, entre 2004 e 2013. Para o tratamento das informações, recorreu-se à análise de conteúdo de Bardin (2011) e como aporte metodológico recorreu-se a Bourdieu (1989, 1996, 2003 e 2014) e Coelho (2015; 2016A, 2016B). Os resultados revelam que o estudo sobre as sociabilidades adolescentes neste período apresentam a violência como principal agente influenciador de sociabilidades entre adolescentes escolares, além de indicarem a escola como lugar de sociabilidades, logo passível de rearranjos nas relações de poder presentes na mesma, o que ratifica a importância sobre o estudo das sociabilidades adolescentes na Escola Básica.

PALAVRAS-CHAVE: Educação; Sociabilidades adolescentes; Escola básica. 


\title{
Adolescents sociabilities in the basic school: state of art 2004-2013
}

\begin{abstract}
This research aims to analyze what Theses and Dissertations say about adolescents sociabilities in the Basic School, defended in Brazilian Postgraduate Programs between 2004 and 2013; For the treatment of the information, we used the content analysis of Bardin (2011) and as a methodological contribution we used Bourdieu (1989, 1996, 2003 and 2014) and Coelho (2015; 2016A, 2016B). The results show that the study on teenage sociabilities in this period presents violence as the main influencing agent of sociabilities among school adolescents, besides indicating the school as a place of sociability, soon to be rearranged in the relations of power present in the same, which ratifies The importance on the study of adolescent sociabilities in the Basic School.
\end{abstract}

KEYWORDS: Education; Young sociabilities; Basic school.

\section{Introdução}

A tradição dos estudos sobre adolescentes, especialmente no Brasil, ocupa-se majoritariamente de problematizar esta condição por duas categorias-chave: a violência e a sexualidade. Recentemente, outras categorias surgiram para ampliar os estudos sobre a adolescência e sobre adolescentes, ancoradas principalmente nas Ciências Sociais, dentre elas o estudo das Sociabilidades Adolescentes, ocupada de entender como as relações sociais interferem na construção da condição adolescente.

Não queremos aqui responsabilizar a escola pelos constantes casos de violência entre seus estudantes, mas também não podemos fechar os olhos para o fato de a violência entre adolescentes tratar-se de um problema constante; e que a escola precisa confrontá-lo urgentemente. A saída talvez esteja em desenvolver um currículo voltado para a valorização das diversidades de seus alunos e suas alunas, visto que o ensino tradicional não contempla uma ação socializadora para a maioria destes(as) (CONTINI; KOLLER; BARROS, 2002; COELHO, 2016a, 2016b), e cada vez mais resulta em casos como o do estudante que morreu após uma briga com um colega, em Belo Horizonte; ou do adolescente que morreu após ter sido espancado em uma escola pública da cidade de Belém do Pará, ou da adolescente candomblecista, agredida por uma colega de turma, motivada por intolerância religiosa; ou, ainda, do estudante de uma escola estadual na zona sul de São José dos Campos (SP), espancado a pauladas por adolescentes, em frente à escola, motivados por homofobia; dentre tantos outros, que, infelizmente, estão cada vez mais comuns em nossos noticiários Brasil afora, nos apresentando uma escola passiva e direta ou indiretamente conivente com a manutenção de hierarquias (BOURDIEU, 1989; 1996) que justifiquem esse desvio de comportamento entre seus estudantes.

Diante de tal fenômeno, analisaremos Teses e Dissertações produzidas em diferentes Programas de Pós-graduação brasileiros, no período compreendido entre 2004 e 2013 e disponibilizadas na Biblioteca Digital Brasileira de Teses e Disserta- 
ções - BDBTD, em busca de traçarmos um panorama analítico sobre as Sociabilidades Adolescentes na Escola Básica, e tentando estabelecer relações entre a produção brasileira nesta temática e as influências desta produção para a construção do conhecimento sobre sociabilidades adolescentes. Esta pesquisa, portanto, adentra em um campo em crescimento contínuo, mas que, em determinado momento da história de seus estudos, suas representações de dominância ainda não estavam bem definidas a exemplo das Teses e Dissertações que aqui analisaremos.

A partir da análise do Conteúdo, segundo Bardin (2011), entendida como conjunto de técnicas de análises das comunicações que tem como objetos as mensagens e como objetivo a manipulação destas mensagens, que possibilitem inferências de outras realidades que não a expressa ipsis litteris na mensagem estudada. Ocupamonos de analisar e compreender o que nos dizem esses trabalhos sobre a realização das "sociabilidades adolescentes" presentes no período em questão, buscando identificar as possíveis lacunas e apontar caminhos para enriquecer o debate deste fenômeno no campo acadêmico.

Em caráter explicativo, afirmamos que os dados foram categorizados de acordo com os conceitos de Laurence Bardin (2011), possuindo, portanto, certas qualidades como: meio de exclusão mútua - cada elemento só pode existir em uma categoria; homogeneidade - para definir uma categoria, é preciso haver só uma dimensão na análise; pertinência - as categorias devem dizer respeito às intenções do investigador, aos objetivos da pesquisa às questões norteadoras, às características da mensagem, etc; objetividade e fidelidade - se as categorias forem bem definidas, se os temas e indicadores que determinam à entrada de um elemento numa categoria forem bem claros, não haverá distorções devido à subjetividade dos analistas; e produtividade - as categorias serão produtivas se os resultados forem férteis em inferências, em hipóteses novas, em dados exatos; para apresentar de forma condensada os dados em bruto buscando torna-los significativos e válidos. Passaremos, então, a partir da sessão seguinte, ao estudo sobre os ditos e não ditos nas Teses e Dissertações, por nós analisadas nesta pesquisa. Analisamos, ao todo, vinte e um trabalhos de conclusão de curso de Programas de Pósgraduação de diferentes regiões do Brasil, defendidos entre 2004 a 2013, com exceção da região norte que não apresenta Tese ou Dissertação sobre esta temática neste período. A organização dos trabalhos aconteceu em três fases complementares: pré-análise, exploração do material, e tratamento dos resultados, inferências e interpretações. Seguindo as orientações de Bardin (2011, p. 95), a pré-análise consistiu na organização e sistematização das ideias iniciais para assim facilitar o desenvolvimento da pesquisa; a exploração do material consistiu em ler e selecionar os trabalhos que foram analisados; e o tratamento dos resultados, inferências e interpretações consistiram na separação e no tratamento dos trabalhos em categorias que facilitarão o mapeamento pretendido e a análise final dos mesmos que apresentaremos nas seções seguintes. 


\section{O que dizem as teses e dissertações defendidas nos programas de pós-graduação brasileiros, no período de 2004 a $2013 ?$}

O primeiro ponto a considerar sobre as Teses e Dissertações por nós analisadas, é que há divergência quanto ao entendimento de "adolescentes" e "adolescência". Essa divergência nos demonstra uma falha no debate desta fase do desenvolvimento humano e, como a maioria das pesquisas analisadas pertence ao campo da educação, isto nos permite inferir que a escola continua desconhecendo seus estudantes e as necessidades educacionais para esta faixa etária.

Dos(as) autores(as) analisados, apenas Meinerz (2005), Ferreira (2012), Tigre (2013), Ferrão (2011), e Santos (2007) demarcam a adolescência a partir da faixa etária prevista pelo Estatuto da Criança e do Adolescente - ECA (2002), que apresenta o adolescente como aquele pertencente à faixa etária compreendida entre doze e dezoito anos de idade; e concebem adolescentes como sujeitos que não estão apenas "experimentando uma fase da vida que irá passar, mas vivenciando seus processos indissociáveis de constituição individual e social, seus processos de identização" (MEINERZ, 2005, p. 84); vistos como "fruto de uma sociedade, cujos valores foram forjados sem que houvesse um parâmetro para limites" (FERREIRA, 2012, p. 92); e necessitados de um adulto que lhes ofereça "regulação comportamental, sentimentos, postura, entre outras formas de convivência" (SANTOS, 2007, p. 37), para assim, aprenderem "um conjunto de ideias, sentimentos e de práticas comuns indispensáveis" (FERRÃO, 2011, p. 80) e que também encontram nos seus pares "um espaço para expressar emoções, sentimentos, dúvidas e ansiedades e é com eles que aprendem formas de condutas adequadas a sua idade, gênero e condição social” (TIGRE, 2013, p. 156).

No entanto, autores(as) como Brum (2004), Lima (2005), Callegaro (2007), Barbosa (2007), Villas (2009), Leite (2011) e Pouzas (2012) alocam adolescentes dentro de uma categoria mais ampla e mais genérica: a juventude. Esta, por sua vez, é definida nos trabalhos analisados como "grupo de jovens e comportamentos que fogem aos padrões de socialização aos quais deveriam estar submetidos” (BRUM, 2004, p. 50); como "um momento da vida onde são comuns irrupções violentas" (LIMA, 2005, p. 83); vivência de "diferentes lógicas: família, lazer, cultura, trabalho, etc, podendo assumir diferentes identidades". (BARBOSA, 2007, p. 17, grifo nosso); "fase de transição entre a infância (a qual se nega) e a fase adulta (a qual ainda não se é)", ou seja, o sujeito jovem é, invariavelmente, um "vir a ser" (VILLAS, 2009, p. 32). Gelson Leite é o único autor que apresenta a adolescência como fase complementar à juventude, pois ambas constituem uma "fase da vida específica, definida em termos etários, culturais e na relação com a vida adulta" (LEITE, 2011, p. 13); mas que não "define de forma homogênea um grupo de pessoas da mesma ideia” (POUZAS, 2012, p. 29). Carlos Callegaro por sua vez, ciente das complexidades que envolvem o conceito de juventude, afirma-se capaz apenas de apontar "aproximações sobre juventude e não conceituá-la de maneira definitiva" (CALLEGARO, 2007, p. 31), mas cita o que diz uma corrente do conhecimento existente sobre juventude, ligando-a a uma "cultura juvenil, unitária, específica de uma geração definida em termos etários” (ibdem, p. 32). 
$\mathrm{Na}$ contramão das definições categóricas, identificamos um grupo de autores(as) que apresentam dificuldade em categorizar seus investigados nas categorias adolescentes ou juventude: Gonçalves (2007); Vieira (2009); Oliveira (2010); Meirelles (2005); Araújo (2009); Piovani (2012); Uchoga (2012) e Monzeli (2013). Tal dificuldade apresenta-se tanto por diferentes entendimentos do contexto social destes(as) autores(as) sobre os sujeitos alvo de suas investigações, quanto por diferentes visões políticas e ideológicas manifestados a respeito da fase de desenvolvimento humano compreendida entre a infância e a fase adulta que norteia suas pesquisas (CATANI; GIGLIOTI, 2004; MONZELI, 2013).

O segundo ponto a se considerar é o conceito de sociabilidade apresentado nos trabalhos, que remetem-na "como relativa às interações que se estabelecem por opção do indivíduo, destacando-se seu aspecto de ludicidade e de espontaneidade" (MEINERZ, 2005, p. 24), e resultante de relações sociais, econômicas, históricas, objetivas (GONÇALVES, 2007, p. 22), que se concretiza no envolvimento de atores sociais em torno de suas realizações conjuntas (VIEIRA, 2009, p. 10), ou seja, a finalidade em se agrupar é a própria relação e a satisfação ocorre ao estabelecer laços que têm em si mesmos a sua razão de ser (CALLEGARO, 2007, p. 60).

O referencial teórico que fundamenta os trabalhos é formado majoritariamente por Juarez Dayrell (2005), Anthony Giddens (2005), e Bernard Lahire (1997), este especificamente trabalhando a relação estabelecida entre estudantes de origem popular, a escola, os fatores que o conduzem ao fracasso e ao sucesso escolar (É importante destacar, porém, um referencial teórico suplementar, dedicado ao estudo detido sobre processos de sociabilidade na atualidade, apresentado por Villas (2009, p. 26), composto por Costa et al (1990), Heran (1988), Santos (1994), em termos quantitativos; e Abrantes (2003), Barbosa (2007), Forsé (1991), Dias; Lopes(1996); Lopes (1997), Pais (1990), Santos (1994), em termos qualitativos); e por Georg Simmel (1983), teórico mais citado entre os trabalhos, que atrela sociabilidades ao envolvimento de indivíduos ligados por uma motivação autônoma (que pode ser positiva ou negativa) e lúdica realizada conjuntamente para a formação social, ou seja,

(...) tudo o que está presente nos indivíduos (que são dados de qualquer realidade histórica), sob forma de impulsos e interesses, propósito, inclinação, estado psíquico movimento - tudo o que está presente neles, de maneira a engendrar ou mediar influências sobre outros, ou que receba tais influências, designo como conteúdo, como matéria, por assim dizer de sociação. Em si mesmas essas matérias, com as quais a vida é preenchida, as motivações que as impulsionam não são sociais. Estritamente falando, nem fome, nem amor, nem trabalho, nem religiosidade, nem tecnologia, nem as funções e resultados da inteligência são sociais. São fatores de sociação apenas quando transformam o mero agregado de indivíduos isolados em formas específicas de ser com e para um outro - as formas que estão agrupadas sob o conceito geral de interação. (SIMMEL, 1983, p. 166).

É importante salientar que a escola é apresentada, nos trabalhos, como espaço voltado às relações de sociabilidade de seus estudantes, o que nos revela uma ressignificação dessa instituição, cada vez mais valorizada para a realização de interações meramente sociais em detrimento de suas relações formativas. 
Um grupo de autores(as) formado por MEINERZ (2005), MEIRELLES (2005), BARBOSA (2007) e MONZELI (2013) investiga a preferência de estudantes adolescentes por lugares ou espaços não formativos dentro da escola, ou seja, pátios, quadras, banheiros etc. Lugares privilegiados pelos estudantes, para desenvolverem suas sociabilidades enquanto a sala de aula acaba renegada a um espaço figurativo. Estes(as) autores(as) nos sugerem que a escola deveria também apropriar-se desses momentos de sociabilidade entre os estudantes para desenvolver nos diferentes grupos identificados o sentimento de tolerância ao diferente, à diversidade presente na escola, principalmente quando falamos em práticas de Educação Física e em jogos escolares (VIEIRA, 2009), sobre violência, seja ela física (LIMA, 2005; FERRÃO, 2011; FERREIRA, 2012; TIGRE, 2013; MONZELI, 2013) ou simbólica (BRUM, 2004; ARAÚJO, 2009; UCHOGA, 2012), que permeiam o cotidiano escolar, influenciando diretamente nas relações de sociabilidade entre estudantes adolescentes.

Há, como vemos, uma contracultura dentro da Escola Básica, que parte das sociabilidades adolescentes e pode destoar dos objetivos pretendidos pela cultura escolar tradicional para seus(as) estudantes. Estes, por vezes, expressam-se por atitudes delitivas, pautadas na inversão dos valores sociais. Esta conduta resulta em violências na escola, aquela que ocorre no interior dos espaços escolares, entre ou contra estudantes, sem, no entanto, ligar-se diretamente às atividades institucionais da Escola; da escola, aquela que ocorre no campo simbólico, também chamada de violência institucional, manifestada nas discriminações direcionadas a estudantes, por parte de seus profissionais: professores, corpo técnico, funcionários, etc, e motivada por preconceito de ordem social, sexual, religiosa, econômica, etc, baseada na perseguição pessoal e no abuso de poder e autoridade; e contra a escola que ocorre contra tudo o que representa a escola enquanto instituição: patrimônio, professores, saberes, rotina, currículo, etc e que podem afetar a rotina da mesma de forma prejudicial não só ao patrimônio escolar, mas também à função social da instituição.

A demarcação de espaços, a danificação ou destruição total da escola, etc, são alguns dos exemplos de resistência de estudantes contra a forma bancária e imutável da Escola Básica, é como uma forma desesperada de dizer "estamos aqui, olhem para nós!", ao mesmo tempo em que é um aviso aos demais adolescentes de "este é meu espaço, não ultrapasse sem permissão!". A escola, sem saber o que fazer, vê o delito, mas não pune o que o motiva. Pune o delito, mas não corrige o que o motiva, e enquanto não mudar a concepção de suas estratégias de ensino, sua atual constituição institucional, os problemas provenientes desta "cegueira" continuarão sem solução. Eis a importância de investigar, com vagar, tanto a constituição da adolescência, quanto as formas de sociabilidade de nossos estudantes adolescentes, dentro e fora dos muros da Escola Básica.

\section{Os "não ditos" das teses e dissertações sobre sociabilidades adolescentes defendidas entre 2004 e 2013}

Um aspecto negligenciado nos trabalhos sobre sociabilidades adolescentes defendidos entre 2004 e 2013 diz respeito a não ênfase aos danos psicológicos causados pelos "ruídos" nas sociabilidades dos adolescentes escolares analisados nas 
referidas pesquisas. Entendamos por ruídos de sociabilidade, tudo aquilo que perturba e prejudica a tessitura das relações sociais entre os sujeitos envolvidos: preconceito social, de cor, de gênero, de sexualidade, etc, qualquer fator significante que resulte em comportamentos voltados para a violência física e simbólica, contra determinados sujeitos ou grupos de sujeitos, ou seja, tudo o que pode contribuir para o adoecimento físico, mental e espiritual dos sujeitos, no caso de nosso estudo, adolescentes, fazendo -os perderem o interesse pela escola, repetirem de ano, abandonarem a instituição ou, em casos mais desesperadores, tirarem a própria vida.

O termo "ruído" não é comum nas pesquisas do campo da Educação, é mais frequente no campo dos estudos da linguagem para designar os elementos responsáveis por interferências no processo comunicativo de mensagens entre locutor ou emissor - quem emite a mensagem -, e interlocutor ou receptor - quem a recebe ou deveria recebê-la de forma íntegra. Tais ruídos apresentam-se em quatro grupos distintos: a) Físico, de origem externa, são sons presentes no ambiente que interferem diretamente sobre a compreensão ou emissão da mensagem vinculada; b) Fisiológico, de origem interna, ocorre quando qualquer questão fisiológica interfere na compreensão ou emissão da mensagem vinculada; c) Psicológico, também de origem interna, realiza-se na cabeça da pessoa, quando nos distraímos, resultando assim, na não decodificação da mensagem vinculada; e d) Semântico, o ruído se manifesta na incompreensão de mensagens com mais de um sentido ou pelo desconhecimento de assuntos referentes à saberes restritos a determinantes falantes, como jargões médicos e jurídicos, por exemplo.

Uma lacuna estrutural nos trabalhos analisados talvez esteja no fato de que nada falam sobre como as licenciaturas e os cursos de formação continuada de professores, que podem atuar como facilitadores das relações de sociabilidades estabelecidas entre seus estudantes ou enquanto agentes de combate de problemas existentes nos espaços escolares, motivados por quaisquer questões de ordem hierárquica baseada na opressão de uns em benefício de outros(as). Ou seja, esta lacuna aponta para a necessidade de uma formação inicial e continuada de professores(as) voltadas para a atuação com alunos(as) reais e não ideais e com competência e a qualificação condizentes a esse lugar profissional (COELHO; SILVA, 2015).

Vê-se que as escolas, quando estruturadas, seguem um padrão considerado ideal para estimular o ensino aprendizagem e isso transformou a escola em um espaço de angústias aumentadas que, associadas à angústias trazidas de casa, podem transformar a escola em um espaço de guerra, em detrimento de um espaço de conhecimento e afetividade. Temos nesta realidade, portanto, uma lacuna em aberto para a pesquisa das sociabilidades: o afeto! Afeto em espaços escolares: a relação afetiva dos adolescentes nos momentos de alimentação na cantina da escola, por exemplo. Por que não estudar as sociabilidades de estudantes durante os recreios, na hora da merenda? Esta linha de pensamento permanece silenciada na pesquisa científica. Não esqueçamos que compartilhar alimentos é uma característica afetiva de nossa cultura que nos revela afeto, mas não nos referimos aqui à forma romantizada de vivê-lo, e sim no sentido mais genérico que nos induz a investigar "como eu afeto o outro e como o outro me afeta", "como eu me encaixo no jogo de forças que configuram minha interação com o outro?" "como eu me configuro nesse espaço?" e "como esse espaço me transforma?" 
Podemos também estudar o afeto que adolescentes tem com o próprio corpo, frente às mudanças biológicas e hormonais da adolescência. É preciso buscar entender como estes estudantes desenvolvem o afeto com seus próprios corpos, pois, a aparência nesta fase da vida é muito valorizada e pode ser a porta de entrada para a aceitação ou a exclusão social, neste último caso, causando danos quase irreversíveis para a constituição da autoestima do sujeito, prejudicando suas relações sociais até mesmo na fase adulta. Podemos ainda estudar o afeto que determina as escolhas de uns e a exclusão de outros na formação de grupos de trabalho, nas praticas de Educação Física, na formação de grupos para o desenvolvimento das atividades ou na formação dos times nas atividades esportivas e outras formas de interação.

Outra lacuna latente nas pesquisas analisadas, diz respeito às sociabilidades que os adolescentes realizam nas Redes Sociais, pois muitas destas relações iniciam na escola e partem para o espaço virtual, onde há maior liberdade de expressão de sentimentos e pensamentos lícitos e ilícitos. Neste sentido, a rede mundial de computadores adquire status propício para a propagação anônima (já que nem sempre se pode identificar os autores reais dos discursos presentes em seu cyberespaço) de ideologias que normalmente se apresentam veladas no cotidiano das relações sociais em sua modalidade presencial. A importância de estudar as sociabilidades na internet se dá pelo motivo de ser, o cyberespaço, um local em que o acontecimento se produz, independente do fato poder ou não referir-se a uma realidade exterior. (HENN, 2012, p.114); (COELHO; SILVA, 2016A).

O final da década de 90 até o primeiro decênio dos anos 2000 foram marcados pela popularização das redes sociais, principalmente o Twitter, o Orkut e o Facebook, popularização esta maximizada com os avanços tecnológicos na produção de smartphones que possibilitaram a utilização da internet nos aparelhos celulares o que prontamente foi assimilado para o cotidiano do público adolescente. As Teses e Dissertações analisadas, produzidas entre 2004 e 2013, foram, desse modo, produzidas/ defendidas no auge das vivências das redes sociais, um ambiente "livre" de regras, com o atrativo da ausência de barreiras temporais e espaciais e com a quase obrigação de adesão das pessoas que vivem a era moderna do mundo globalizado e capitalista, principalmente a juventude de forma geral (GONÇALVES, 2010). Consequentemente, sendo, portanto, mais um agente de segregação social. Entendê-las como um meio de segregação social é saber que através delas usuários(as) constroem suas relações afetivas a partir da interação à distância entre pessoas que compartilham uma nova relação de espaço-tempo (LEVY, 1996;1997;1998;1999) e assim constroem hierarquias massificadas com a velocidade de um click. Logo, a escola não pode seguir inerte às influencias das redes sociais na constituição social de seus estudantes, principalmente quando falamos no cotidiano de adolescentes que, muitas das vezes, passam mais tempo interagindo de forma voluntária, em uma realidade virtual, propriamente desenvolvendo relações afetivas da vida real, baseadas no diálogo, na interação física e no "olho no olho".

Um caminho possível para a democratização do espaço escolar e para tornar a escola mais próxima da realidade de estudantes adolescentes pode iniciar por trazer para dentro da escola, conteúdos da vida virtual, até mesmo para problematizar 
e descontruir preconceitos, a partir de casos "problema", obtidos nas redes sociais a que estes estudantes têm acesso diário, pois estão quase sempre online. Já que falamos em caminhos, na próxima sessão, discorreremos sobre possíveis caminhos de pesquisa sobre Sociabilidades Adolescentes que podem reforçar o entendimento global desta temática, a partir da produção de Teses e Dissertações de Programas de Pós-graduação em todo o território brasileiro.

\section{Caminhos possíveis para a produção de conhecimento so- bre sociabilidades adolescentes na escola básica}

As lacunas identificadas nas Teses e Dissertações produzidas e defendidas no Brasil, no período de 2004 e 2013, norteiam nosso direcionamento para o entendimento de como se configurou, naquele período, as relações de sociabilidade entre adolescentes, comparando-as com as estabelecidas atualmente seja na escola ou em espaços não formativos, como festas populares, raves e também nas redes sociais, por exemplo.

Como vimos na introdução deste trabalho, a produção dos Programas de Pós-graduação da região Norte apresenta uma lacuna na realização de pesquisas sobre Sociabilidades Adolescentes em todo o seu território, entre 2004 e 2013. Como integramos um Programa de Pós-Graduação em Educação da Região Norte que mantém uma tradição em estudos voltados para a educação no campo, à educação ribeirinha, um caminho interessante para a pesquisa neste programa pode estar no estudo das sociabilidades de adolescentes do sexo feminino, vítimas de escalpelamento, consequência da imprudência de condutores de embarcações que mantém o eixo do motor de seus barcos sem a devida proteção; pois, estas adolescentes, ao voltarem para a escola, quando voltam, são obrigadas a conviverem com a nova condição, entre os demais estudantes que valorizam a imagem como marca de sociabilidade dentro dos espaços da escolares.

Outro caminho investigativo diz respeito à análise da influência do sotaque interiorano ou "caboclo" paraense nas relações de sociabilidades adolescentes na escola básica da capital do estado, a cidade de Belém do Pará, investigando como este fenômeno linguístico pode resultar em ridicularização e exclusão de sujeitos falantes de uma variante linguística diferente daquela privilegiada na escola. Esta temática vai muito além de um preconceito meramente linguístico, pois nos sinaliza a existência de um preconceito social, visto que a escola, ao privilegiar a língua padrão como certa e condenar ao erro seus "desvios", no caso apresentado, o sotaque interiorano ou "caboclo" paraense, revela a superioridade do erudito sobre o popular, logo, as influências de hierarquias herdadas de uma escola tradicional, aristocrática, portanto, centrada na valorização de uma cultura de maior capital cultural, econômico e também dominante (BOURDIEU, 1989; 1996; 2003; 2014), em detrimento de culturas consideradas inferiores, marcadas socialmente através da linguagem e reforçando o ideário popular que nos revela a existência de um lugar social atribuído ao caboclo paraense a partir de um contínuo linguístico que, "no âmbito dessas instituições, são usados preferencialmente estilos monitorados da língua tanto na modalidade escrita quanto na oral" (BORTONI-RICARDO, 2004, p.51-52). Tal proposta justifica-se pela superação do 
preconceito ao qual são submetidos os(as) falantes desta modalidade linguística dentro dos espaços de letramento, em especial a Escola Básica. Justifica-se também pelo aumento da produção interativa digital, realizado por jovens, sobre conteúdo relativos à cultura paraense, onde o sotaque caboclo surge como principal característica privilegiada, principalmente em canais do youtube direcionados ao público adolescente e cada vez mais populares entre os assuntos buscados por este público.

Outro caminho investigativo sobre as sociabilidades adolescentes nas Escolas da região norte do Brasil, devido sua relevância social, diz respeito às sociabilidades de adolescentes homossexuais e transgêneros na escola, em como a escola pode atuar como facilitadora de garantias de permanência digna desses(as) adolescentes na escola até a conclusão de seus estudos e, assim, permitir que mais sujeitos homossexuais e transgêneros possam ter uma realidade diferente daquela em que são obrigadas atualmente a viver, longe da escola e dependentes muitas vezes da exploração sexual de seus próprios corpos para viverem. Tal proposta justifica-se pela necessidade de combater um problema grave que é a homofobia neste país, apontado recentemente como o que mais mata homossexuais e transgêneros no mundo e, contraditoriamente, o que mais "consome" estes sujeitos no mercado da prostituição, e a cidade de Belém não foge à esta dura realidade. Em Belém, dados do Movimento LGBT do Estado mostram que somente em 2009 pelo menos seis travestis foram mortos na região metropolitana. Além destes, muitos outros casos se quer foram registrados, pois ainda trata-se de um assunto que não gera estatística. Muitas pessoas homossexuais e transgêneros são agredidas diariamente, mas temem denunciar o agressor que às vezes está bem próximo, seja na família, seja na vizinhança ou seja na própria escola, por saberem que nada será feito pelas autoridades policiais, além de reforçarem o constrangimento a que homossexuais e transgêneros conhecem há muito tempo. Justifica-se também pela necessidade de fazer da escola um espaço de conscientização e de formação cidadã no sentido de valorização da vida e dos direitos, nossos e do(a) outro(a), mas isso exige um certo repertório teórico por parte dos professores, repertório este que deve ser construído já na formação inicial destes profissionais.

Inclinamos nossas sugestões de caminhos para a pesquisa sobre a temática das Sociabilidades Adolescentes a temas relevantes de nossa contemporaneidade, especificamente da realidade teórica do Programa de Pós-Graduação em Educação da Universidade Federal do Pará, ao qual somos vinculados, mas que podem ser adaptados à realidade sociocultural de outras regiões do país. A temática das sociabilidades adolescentes nos apresenta muitos outros caminhos possíveis para a pesquisa científica e precisa ser estimulada, principalmente nos Programas de Pós-Graduação da região Norte do Brasil que, por muito tempo, manteve-se inerte na produção deste conhecimento, sem atentar para o fato de que, conhecer nossos estudantes adolescentes, suas formas de sociabilidade e suas relações com a Escola Básica é fundamental para a formação docente, para a construção de uma escola verdadeiramente democrática, logo, é fundamental para nossa a atuação enquanto professores. 


\section{Considerações finais}

Finalizando, por enquanto... Vimos que há a predominância de estudos sobre sociabilidade adolescentes na Escola Básica nos campos de conhecimento ligados às humanidades, especificamente no campo da Educação, defendidos entre os anos de 2004 e 2013, que apresentam algumas lacunas estruturais que precisam ser revistas e analisadas com vagar e ratificamos a importância destes trabalhos para a reflexão sobre as sociabilidades vividas entre adolescentes na Escola Básica brasileira.

Neste sentido, compreende-se a necessidade de estudarmos mais de perto como se dão as relações de sociabilidades entre adolescentes na Escola Básica e, assim, identificar como se constroem as hierarquias que norteiam as aproximações entre membros de diferentes grupos e a exclusão dos considerados "estranhos no ninho", mapear os problemas resultantes dessas sociabilidades e traçar metas para corrigi-los, aperfeiçoando assim, o processo formativo desses adolescentes e de suas redes de socialização nos espaços escolares, sejam eles educacionais ou não. É preciso também que a escola aprenda a ver seus/suas estudantes como seres que precisam interagir, socializar, estabelecer laços com outros seres de igual necessidade, muitas vezes longe da rigidez das fileiras das carteiras escolares.

Atentamos, por fim, para a necessidade de olhar para a adolescência como um período importante na formação de nossas identidades, pois nela ocorre boa parte da formação de nosso caráter, a partir da construção de nossos grupos extrafamiliares, em busca de pertencimento, compreensão, cumplicidade, aceitação social entre novos pares. Também atentamos para a importância de uma formação de professores, tanto inicial quanto continuada, voltada para o enfrentamento das demandas advindas dessa fase da vida e para a promoção de uma transformação em seu fazer pedagógico que resulte em uma mudança efetiva e também qualitativa no processo de ensino-aprendizagem no cotidiano da Escola Básica e ratificamos a urgência de conhecer nossos estudantes adolescentes, suas formas de sociabilidade e suas relações com a Escola Básica para, de posse de tal conhecimento, traçarmos as melhores estratégias de nossa atuação docente.

\section{Referências}

ARAÚJO, Maria Dolores Pinto. Escola, criança favelada e processos de socialização: estudo sobre padrões de socialização no ambiente familiar e na escola. 2009. 126 f. Dissertação (Mestrado em Educação) - Pontifícia Universidade Católica de São Paulo. 2009.

BARDIN, Laurence. Análise de Conteúdo. Lisboa: Edições 70, 2011.

BARBOSA, Daniele de Souza. “Tamo Junto e Misturado!”: um estudo sobre sociabilidade de jovens alunos em uma escola pública. 2007.191 f. Dissertação (Mestrado em Educação) - Universidade Federal de Minas Gerais - UFMG. Belo Horizonte, 2007.

BORTONI-RICARDO, S. Educação em língua materna: a Sociolinguística em sala de aula. São Paulo: Parábola Editorial, 2004.

BOURDIEU, Pierre. O Poder Simbólico. Rio de Janeiro: Editora Bertrand, 1989.

BOURDIEU, Pierre. Razões Práticas: sobre a teoria da ação. Campinas, SP: Papirus Editora, 1996. 
BOURDIEU, Pierre. A Dominação Masculina. 3 ed. Rio de Janeiro: Bertrand Brasil, 2003.

BOURDIEU, Pierre. Escritos de Educação. 15. ed. Petrópolis RJ: Vozes, 2014.

BOURDIEU, Pierre; ASSERON, Jean-Claude. A Reprodução. Petrópolis RJ: Vozes, 2014.

BRASIL. Resolução n. 2, de 10 de julho de 2015. Define as Diretrizes Curriculares Nacionais para a formação inicial em nível superior (cursos de licenciatura, cursos de formação pedagógica para graduados e cursos de segunda licenciatura) e para a formação continuada. 2015.

BRASIL. Lei federal no 8069, de 13 de julho de 1990: estatuto da criança e do adolescente. Rio de Janeiro: Imprensa Oficial, 2002.

BRUM, Dalva Marisa Ribas. Expressões Juvenis na Cultura Escolar: um olhar para a escola pública. 2004. 129 f. Dissertação (Mestrado em Sociologia) - Programa de Pós-Graduação em Sociologia Política da Universidade Federal de Santa Catarina, Florianópolis, 2004.

CALLEGARO, Carlos Augusto. Juventude(s) e escola: suas culturas em diálogo. 2007. 143 f. Dissertação (Mestrado em Educação) - Centro de Ciências da Educação da Universidade Federal de Santa Catarina - UFSC, 2007.

CATANI, Afrânio Mendes; GIGLIOTI, Renado de Souza Porto. Culturas Juvenis: múltiplos olhares. São Paulo: Editora da UNESP, Coleção paradidáticos (Série Cultura), 2004.

CONTINI, Maria de Lourdes Jeffery; KOLLER, Silvia Helena; BARROS, Monalisa Nascimento dos Santos. Adolescência e Psicologia: concepções, práticas e reflexões críticas. Rio de Janeiro/RJ: Conselho Federal de Psicologia, 2002.

COELHO, Wilma de Nazaré Baía; SILVA, Carlos Aldemir Farias da. Formação de Professores no Brasil: notas e contextos. Revista Documento/monumento. Vol. 15.N.1. set. 2015. Disponível em: , <<https://ufpa.academia.edu/WilmadeNazar\%C3\%A9Ba\%C3\%ADaCoelho > . Acesso em: 07 de novembro de 2016.

COELHO, Wilma de Nazaré Baía; COELHO, Mauro Cezar. Lugar de Formação: A produção Intelectual Sobre Ensino de História na Pós-Graduação Stricto Sensu na Região Norte. Revista História \&Ensino, Londrina, v.21, n.2, p. 181-207, jul./dez.2015. Disponível em: <https:// ufpa.academia.edu/WilmadeNazar\%C3\%A9Ba\%C3\%ADaCoelho >. Acesso em: 07 de novembro de 2016.

COELHO, Wilma de Nazaré Baía; COELHO, Mauro Cezar. Preconceito e Discriminação para Além da Sala de Aula: sociabilidades e cultura juvenil no ambiente escolar. In.: COELHO, Wilma de Nazaré Baía; MÜLLER, Tânia Maria Pedroso; SILVA, Carlos Ademir Farias da. (Org.). Formação de Professores, livro didático e Escola Básica. São Paulo: Livraria da Física, 2016.A

COELHO, Wilma de Nazaré Baía; SILVA, Carlos Aldemir Farias da. Preconceito, Discriminação e Sociabilidades na Escola Básica. In.: COELHO, Wilma de Nazaré Baía; MÜLLER, Tânia Maria Pedroso; SILVA, Carlos Ademir Farias da. (Org.). Formação de Professores, livro didático e Escola Básica. São Paulo: Livraria da Física, 2016.B

COELHO, Wilma de Nazaré Baía; SILVA, Carlos Aldemir Farias da. Formação de Professores no Brasil: notas e contextos. Revista Documento/monumento. Vol. 15.N.1. set. 2015. Disponível em: <https://ufpa.academia.edu/WilmadeNazar\%C3\%A9Ba\%C3\%ADaCoelho>.Acesso em: 07 de novembro de 2016.

FERRÃO, Aline de Araújo. A violência na Escola e o seu papel de Socialização. 2011. 109 f. Dissertação (Mestrado em Ciências Sociais) - Instituto de Filosofia e Ciências Humanas, Universidade do Estado do Rio de Janeiro. 2011.

FERREIRA, Antônio Eustáquio. Função Paterna e Sociabilidade Violenta em Jovens escolares. 2012. 271 f. Tese (Doutorado em Psicologia) - Programa de Pós-Graduação Stricto Sensu em Psicologia, Pontifícia Universidade Católica de Goiás, 2012. 
GONÇALVES, Lilia Neves. Educação Musical e Sociabilidade: um estudo em espaços de ensinar/aprender música em Uberlândia-MG nas décadas de 1940 a 1960. 2007. 333 f. Tese (Doutorado em Música) - Programa de Pós-Graduação em Música, Universidade Federal do Rio Grande do Sul, Porto Alegre, 2007.

GONÇALVES ,R. PATRÍCIO E V. Facebook: rede social educativa? Disponível em: <https:// bibliotecadigital.ipb.pt/bitstream/10198/3584/1/118.pdf 2010>. Acesso em: 14 nov. 2016.

HENN, Roanldo Cesar, et.al. Transformações do Acontecimento nas redes Sociais: das mobilizações contra a homofobia à crise de dupla sertaneja. Brazilian Journalism Researche: Mídias Digitais, Convergências e Prática Jornalística: desafios e perspectivas. V. 8. N¹, 2012.

LEITE, Gelson Antonio. Juventude e Socialização: os modos do ser jovem aluno das camadas médias em uma escola privada de Belo Horizonte - MG. 2011.190 f. Dissertação (Mestrado Acadêmico em Educação) - Faculdade de Educação, Universidade Federal de Minas Gerais, 2011.

LEVY, Pierre. O que é o virtual?. São Paulo: Ed. 34, 1996;

LEVY, Pierre. As tecnologias da inteligência. São Paulo: Ed. 34, 1997;

LEVY, Pierre. A máquina universo. Porto Alegre: ArtMed, 1998;

LEVY, Pierre. Cibercultura. São Paulo: Ed. 34, 1999

LIMA, Emanoel José Batista de. Adolescentes e Jovens e suas Bases de Apoio: relações de amizade com suporte social no enfrentamento à violência. 2005. 128 f. Dissertação (Mestrado em Psicologia) - Programa de Pós-Graduação em Psicologia, Universidade Federal do Rio Grande do Norte, 2005.

MEINERZ, Carla Beatriz. Adolescente no pátio, outra maneira de viver a escola: um estudo sobre a sociabilidade a partir da inserção escolar à periferia urbana. 2005.206 f. Tese (Doutorado em Educação). Universidade Federal do Rio Grande do Sul, 2005.

MEIRELLES, Mauro. As Redes que se Tecem nas Escolas Públicas de Ensino Médio de Porto Alegre: o uso das tecnologias digitais e construção de indicadores de fluência digital a partir de uma abordagem sociotécnica. 2005. 309 f. Dissertação (Mestrado em Educação) Programa de Pós-Graduação em Educação, Universidade Federal do Rio Grande do Sul, Porto Alegre, 2005.

MONZELI, Gustavo Arthur. Em Casa, na Pista ou na Escola é Tanto Babado: espaços de sociabilidade de jovens travestis. 2013. 101 f. Dissertação (Mestrado em Terapia Educacional) - Programa de Pós-graduação em Terapia Ocupacional, Universidade Federal de São Carlos, 2013.

OLIVEIRA, Rogério Cruz de. Na "Periferia" da Quadra: Educação Física, cultura e sociabilidade na escola. 2010. 188 f. Tese (Doutorado em Educação Física) - Faculdade de Educação Física da Universidade Estadual de Campinas, 2010.

PIOVANI, Verônica Gabriela Silva. Escola, Tecnologia e Sociabilidade na Educação Física: intercâmbios pedagógico-culturais no âmbito do Plano CEIBAL e do PROUCA. 2012. 214 f. Dissertação (Mestrado em Educação Física) - Programa de Pós-Graduação em Educação Física - Universidade Federal de Santa Catarina, 2012.

POUZAS, Ubiratan Santos. Lazer, Juventude E Ensino Médio/Técnico: um estudo sobre as tensões estabelecidas entre os processos de escolarização e lazer no Coltec. 2012.126 f. Dissertação (Mestrado em Educação Física) - Programa de Mestrado em Lazer da Escola de Educação Física, Fisioterapia e Terapia Ocupacional, Universidade Federal de Minas Gerais, 2012.

RAMIREZ, Rosa Eulógia. Perfil dos Valores Juvenis Contemporâneos: uma análise comparativa entre escolas particulares e públicas da capital e do interior do Estado do Rio Grande do Sul. 2008. 131 f. Dissertação (Mestrado em Ciências Sociais) - Programa de Pós-Graduação em Ciências Sociais, Universidade do Vale do Rio dos Sinos, 2008. 
SANTOS, Claudemir José dos. Futebol se Aprende na Escola: novas práticas de sociabilidade esportiva no contexto urbano. 2007. 130 f. Dissertação (Mestrado em Ciências Sociais) - Programa de Pós-Graduação em Ciências Sociais do Centro de Educação e Ciências Humanas, Universidade Federal de São Carlos, 2007.

SIMMEL, Georg. Sociabilidade: um exemplo de sociologia pura ou formal. In: MORAIS FILHO, Evaristo (org.), Simmel. São Paulo: Ática, (Coleção Grandes Cientistas Sociais), 1983.

TIGRE, Maria das Graças do Espírito Santo. Escola, Juventude e Violência: um estudo no ensino médio. 2013. 242 f. Tese (Doutorado em Educação) - Programa de Pós-Graduação em Educação, Universidade Federal de São Carlos, 2013.

UCHOGA, Liane Aparecida Roveran. Educação Física Escolar e Relações De Gênero: risco, confiança, organização e sociabilidades em diferentes conteúdos. 2012.191 f. Dissertação (Mestrado Acadêmico em Educação Física) - Universidade Estadual De Campinas, 2012.

VIEIRA, Inês Almeida. "Delicadeza e Espírito de Grupo": o basquetebol como invenção cultural. 2009. 173 f. Tese (Doutorado em Sociologia) - Programa de Pós-Graduação em Sociologia - Universidade Federal do Ceará, 2009.

VILLAS, Sara. Formas de Sociabilidade entre Alunos de uma Escola de Ensino Médio/Técnico. 2009. 228 f. Dissertação (Mestrado em Educação) - Programa de Pós-Graduação em Educação, Universidade Federal de Minas Gerais, 2009.

* Mestre em Educação pela Universidade Federal do Pará, Belém, Pará, Brasil.

** Professora doutora da Universidade Federal do Pará, Belém, Pará, Brasil.

\section{Correspondência}

Wilma de Nazaré Baía Coelho - Universidade Federal do Pará, Faculdade de História/Instituto de Filosofia e Ciências Humanas. Rua Augusto Corrêa - até 937 - lado ímpar. Guamá. CEP: 66075110. Belém, Pará, Brasil.

E-mail: andersonptk.rodrigues@gmail.com - wilmacoelho@yahoo.com.br

Recebido em 25 de abril de 2017

Aprovado em 16 de outubro de 2017 